Iranian Quarterly Journal of Breast Disease. 2019; 12(3):47.

\section{Original Article \\ The Effect of Acceptance and Commitment Therapy Adopted for Couples Compared with Integrative Couple Therapy on Marital Conflicts of Couples with Breast Cancer}

\author{
Ahmadzadeh L', Vaezi $\mathbf{M}^{2 *}$, Sodagar $\mathrm{SH}^{3}$, Bahrami hidaji $\mathbf{M}^{3}$, Golmohammad \\ Nazhad Bahrami GH ${ }^{4}$ \\ ${ }^{1} \mathrm{PhD}$ student in Health Psychology, Faculty of Psychology and Educational Sciences, \\ Karaj University, Karaj, Iran \\ ${ }^{2}$ Alzahra Medical Training Center, Faculty of Medical Sciences, Tabriz University of \\ Medical Sciences, Tabriz, Iran \\ ${ }^{3}$ Department of Psychology, Faculty of Psychology and Educational Sciences, Karaj \\ University, Karaj, Iran \\ ${ }^{4}$ Department of Psychology, Faculty of Psychology and Educational Sciences, \\ Azarbaijan Shahid Madani University, Tabriz, Iran
}

Receive: 4/6/2019

Accepted: 14/9/2019

*Corresponding Author: mva260@yahoo.com

Ethics Approval: IR.IAU.k.REC.1397.28

\begin{abstract}
Introduction: The aim of this study was to determine the efficacy of acceptance and commitment therapy adopted for couples with integrative couple therapy in improving marital conflicts of couples with breast cancer.

Methods: In this semi-experimental study, a pre-post design was used. Using available sampling, we approached 200 couples facing breast cancer referred to the educational and therapeutic center of Alzahra Hospital in Tabriz and enrolled 45 couples with the highest scores on the Marital Conflict Questionnaire in the study. They were randomly divided into three groups: two experimental groups and one control group. One of the experimental groups received 8 consecutive 90-minute sessions of acceptance and commitment therapy adopted for couples, and the other experimental group received 16 sessions of integrative couple therapy. The control group did not receive any intervention. The research tool was the Marital Conflict Questionnaire. Data were analyzed using analysis of covariance.
\end{abstract}

Results: The treatment based on acceptance and commitment therapy was effective in reducing marital conflict $(\mathrm{P}<0.05)$. Integrative couple therapy, too, reduced marital conflict in women with cancer $(\mathrm{P}<0.05)$. There was no significant difference between the two treatment modalities $(\mathrm{P}>0.05)$.

Conclusion: Both acceptance and commitment therapy and integrative couple therapy are effective approaches to solving couples' individual and communicative problems.

Keywords: Acceptance and Commitment Therapy, Integrated Couple Therapy, Marital Conflicts 


\section{زوجى با زوج درماذى يكيارٌهنكر بر تعارضات زناشويى زوجين داراى همسر مبتلا به سرطان يستان}

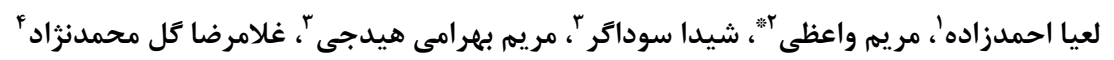
' دانشجوى دكترى روانشناسى سلامت، دانشكده روانشناسى و علوم تربيتى، دانشعاه آزاد اسلامى واحد كرج، كرج،

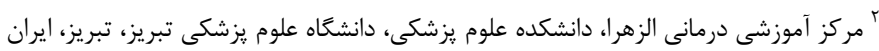

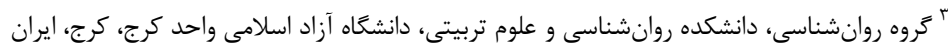

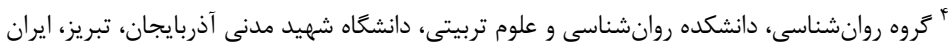

مقدمه: اين يزوهش با هدف مقايسه اثر بخشى درمان مبتنى بر يذيرش و تعهد انطباق يافته زوجى با

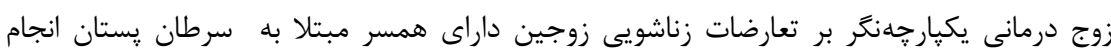

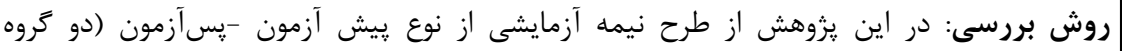

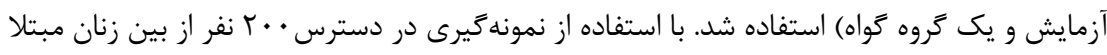

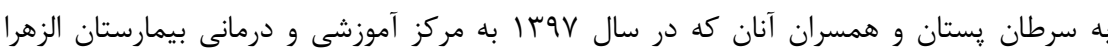

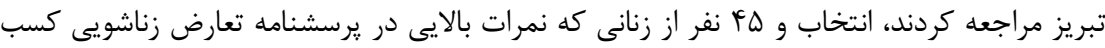

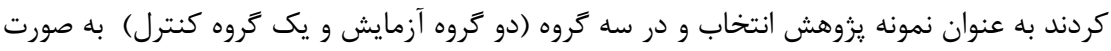

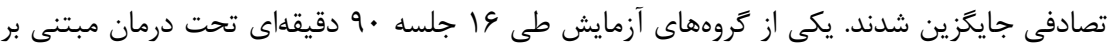

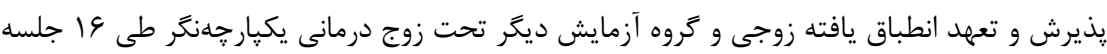

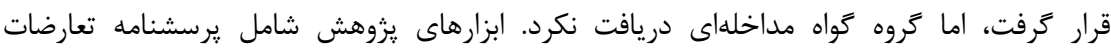

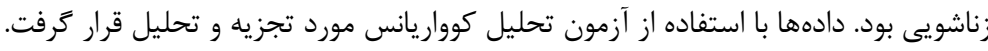
يافتهها: نتايج نشان داد درمان مبتنى بر يذيرش و تعهد انطباق يافته زوجى بر كاهش تعارض

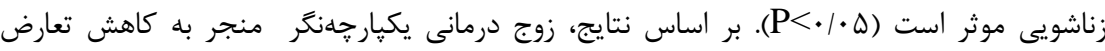

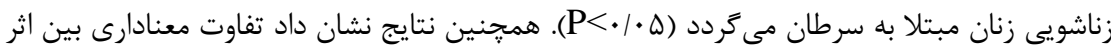

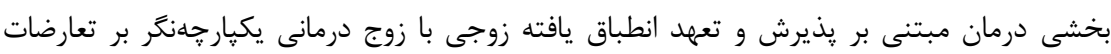

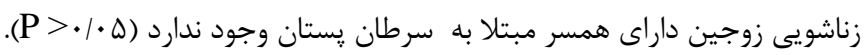

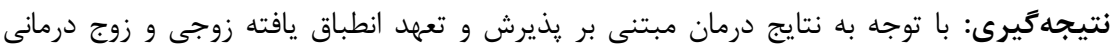

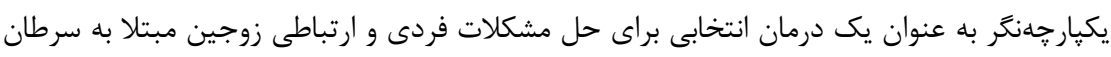

$$
\text { يستان به كار برده شود. }
$$

وازمهاى كليدى: درمان يذيرش و تعهد، زوج درمانى يكيار حهنكَ، تعارضات زناشويى 
روابط زناشويى يا انخيزشهاى يِيجيده شان موجب

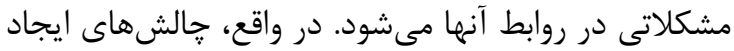

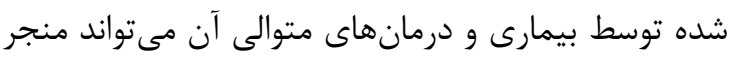

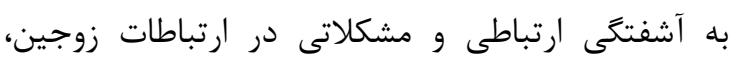

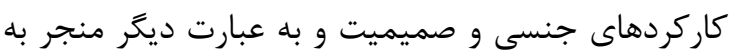

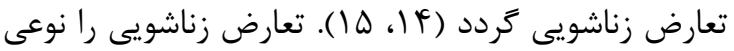

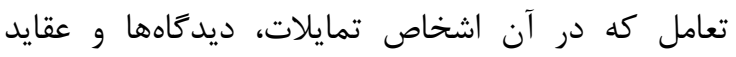

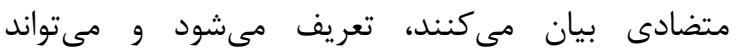
ييشدرآمد جدايى زوجها محسوب شود. تعارضات زناشويى

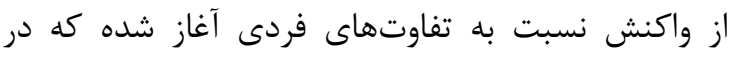
صورت شدت يافتن آن، احساس خشه، كينه، نفرت، حسادت و سو رفتار كلامى و فيزيكى بر روابط زن و شوهر إن إنسات حاكم مىشود و تعارضات در اين حالت به صورت نا نا بهنجار

بروز مى كند (1) (1). از آنجا كه مداخله كروهى زوج محور يك مداخله ساختار يافته و مبتنى بر مهارت بوده و شامل حمايت هيجانى بين

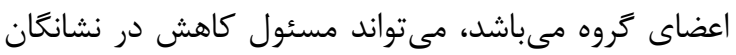

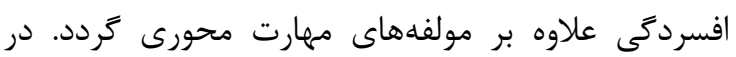
حقيقت، يكى از مزاياى كروهها براى اشخاصى كه استرس

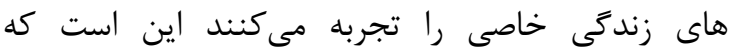

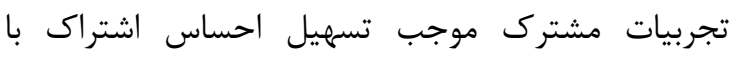
اعضاى گروه مىشود و بنابراين موجب كاهش انزواى فرد مى كردد (IV). با اين حال، تحقيقات كذشته تاثيرات

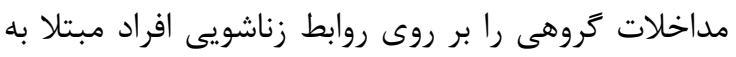
سرطان مخصوصا يستان را كمتر مورد ارزيابى قرار دادهاند. در درمان مبتنى بر يذيرش و تعهد فرض بر اين است كه

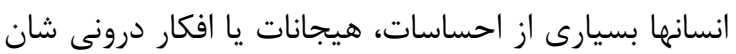

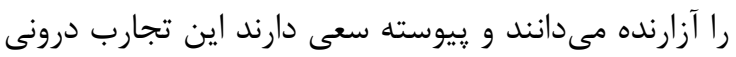

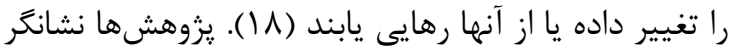
اين هستند كه تلاش در فرونشاندن افكار و احساسات منفى، و اجتناب از سبكهاى مقابلهاى در واقع مشكلات روانشناختى در طولانى مدت ايجاد مى كند و انعطاف

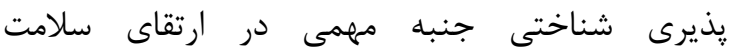

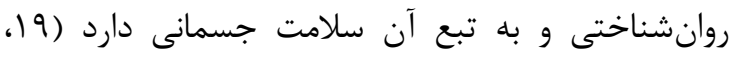

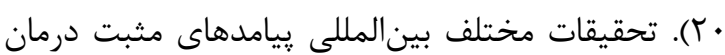
مبتنى بر يذيرش و تعهد را در مطالعات خود در مورد

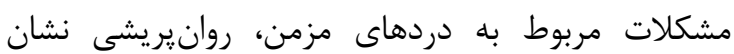

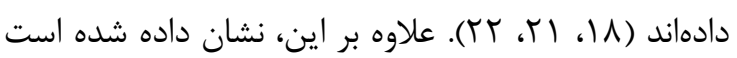
كه اين درمان در كاهش افسردىى و اضطراب بيماران
مقدمه

با وجود پيشرفتهاى فراوان در عرصه علم يزشكى و توسعه دانش بشرى در مهار و درمان انواع بيمارىها،

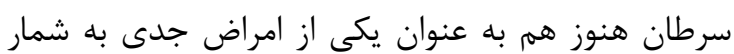

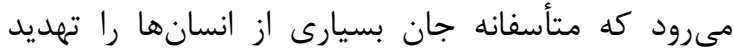

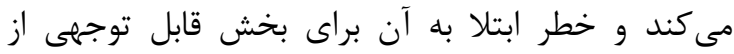

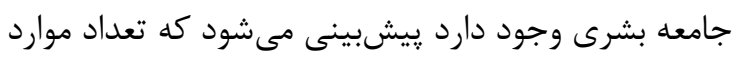

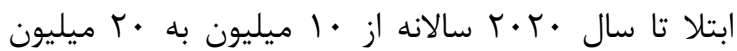

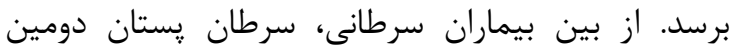

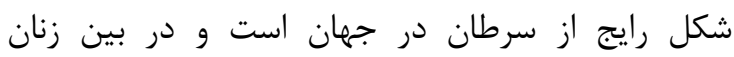

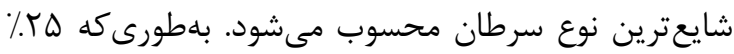
از كل سرطانها را در زنان تشكيل مىدهد (1). ابتلا به

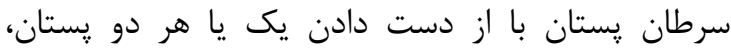
احساس ناشى از قطع عضو را در يك فرد ايجاد مى كنند.

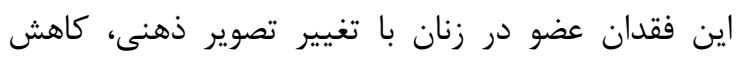
احساس زنانه، كاهش حس جذابيت و جاذبه جنسى و نيز

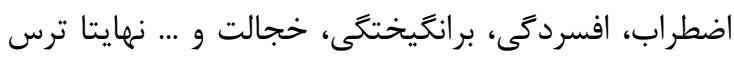

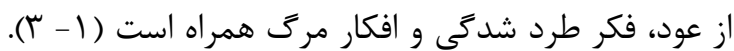
مشخص شده است كه سرطان بستان بر روابط زناشويى

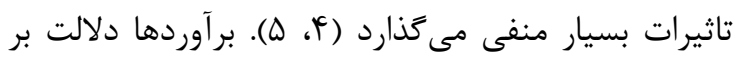

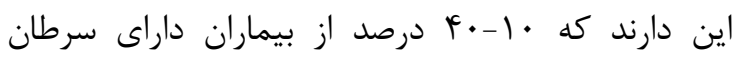
يستان تغييرات منفى در روابط زناشويى را كزارش كردهاند

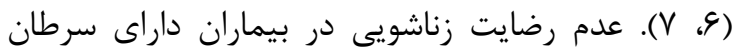

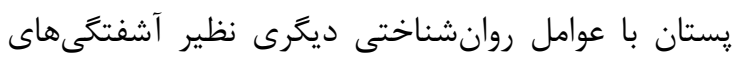
هيجانى/ خطر افزون شده افسردگى و كيفيت زندانى مرتبط هست (9). اين عوامل به نويه خود پيش ريشبينى

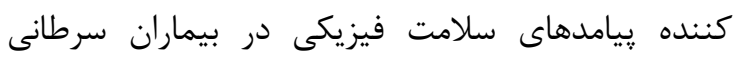

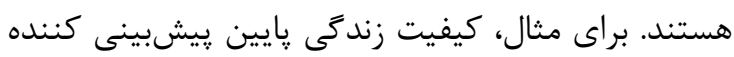
دوره بقا و پاسخ به درمان در مراحل بيشرفته سرطان

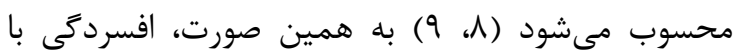
ريسك بالاى مرى در اين بيماران ارتباط دارد ( •(، (1) (1). از طرف ديكر، تحقيقات نشان مىدهند كه زنان داراى

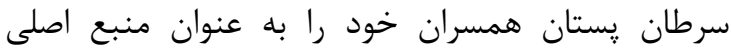

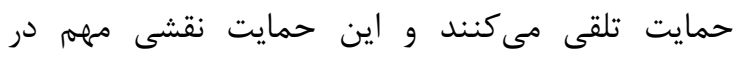

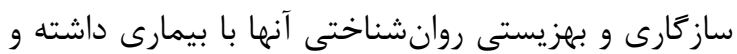

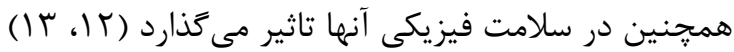

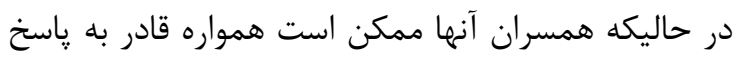

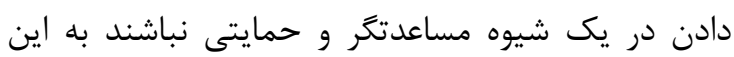

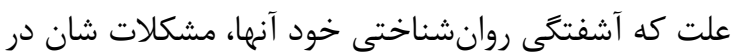


كروهى مبتنى بر يذيرش و تعهد را با يكى از درمانهاى

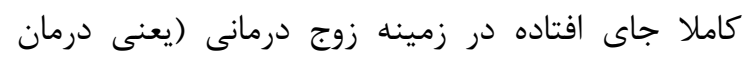

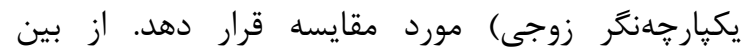

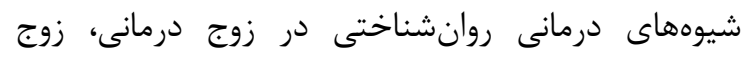

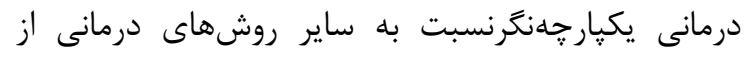

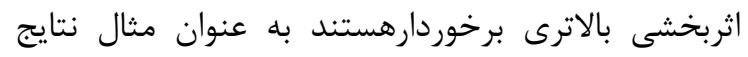
يافته هاى يزوهشى كودوينَ و همكاران (• (1)، ديويد

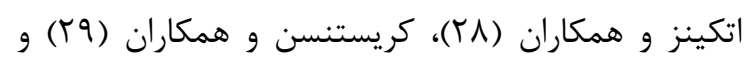

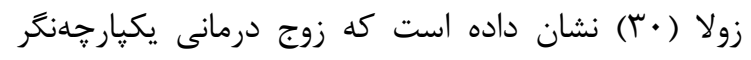

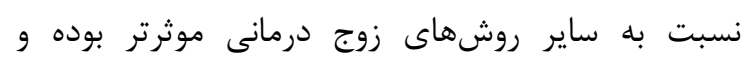
اثربخشى نسبتا بالاترى داشته است.

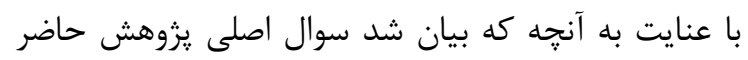

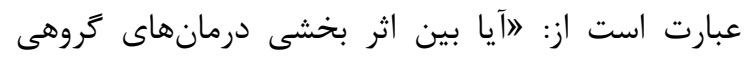

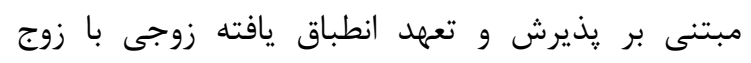

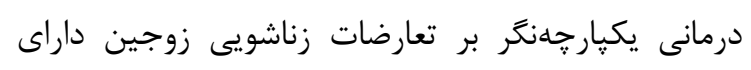

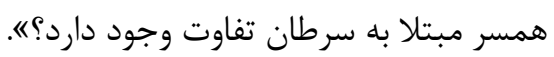

\section{مواد و روشها مهند}

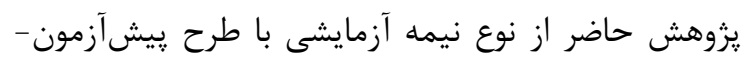

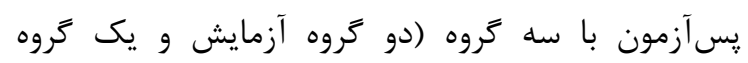

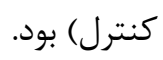
جامعه، نمونه و روش نمونه كيرى: جامعه آمارى اين

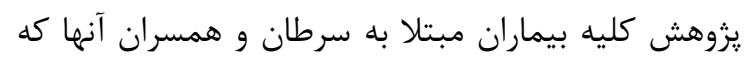

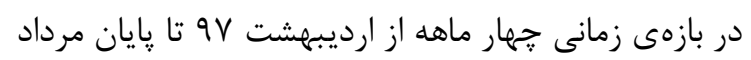
9V به مركز آموزشى و درمانى بهار بيمارستان الزهرا تبريز

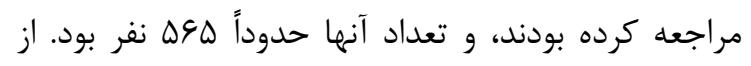

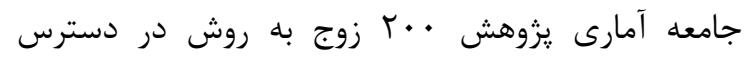

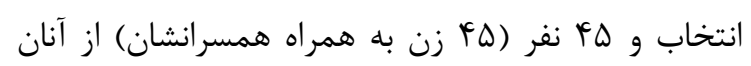

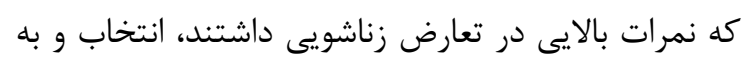

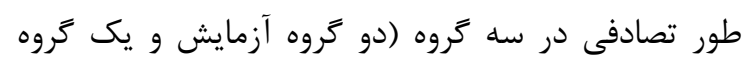

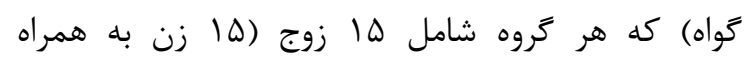

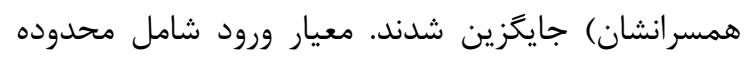

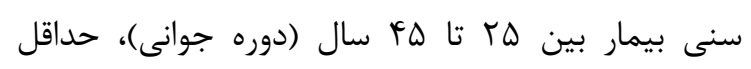

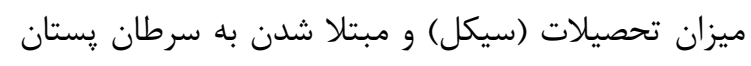

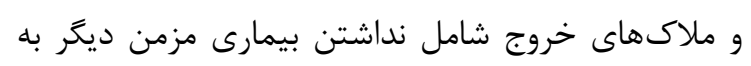

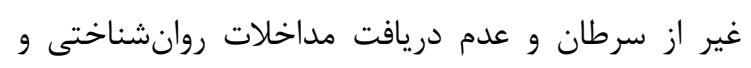
روانيزشكى طى يك سال كذشته بودند. ملاحظات اخلاقى إنى

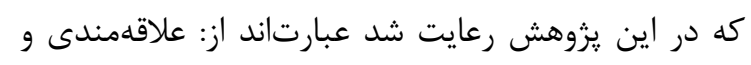
رضايت كامل به مشاركت در تحقيق، محرمانه ماندن
سرطانى موثر واقع شده است (Tr). درمان مبتنى بر

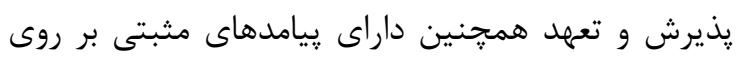

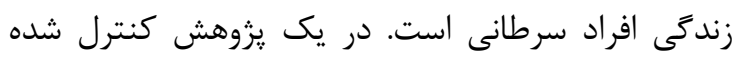

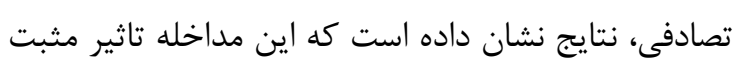

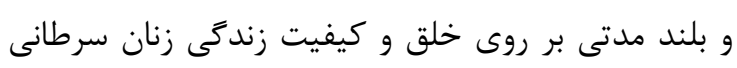

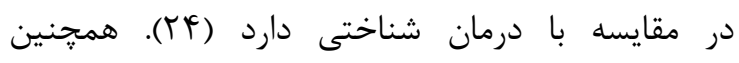

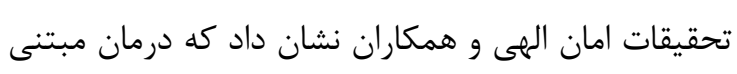

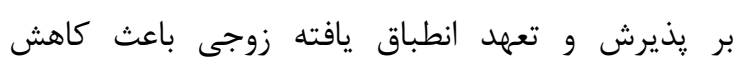

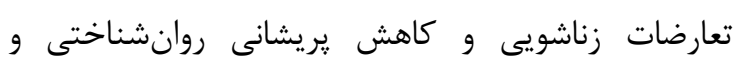

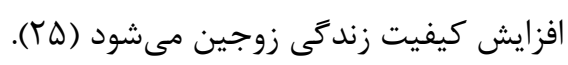

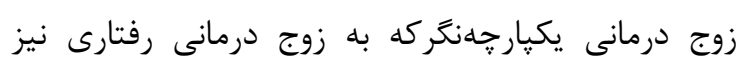

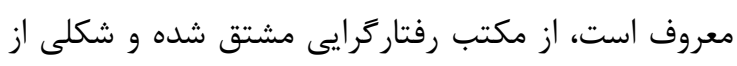

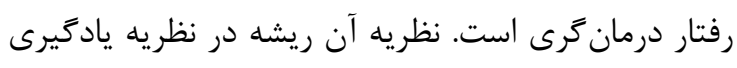

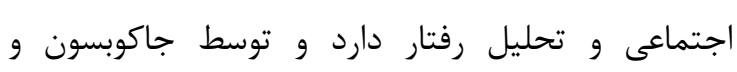

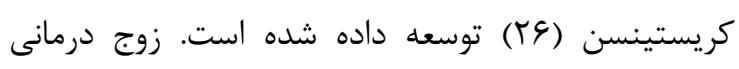

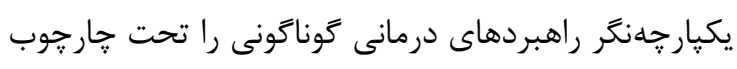

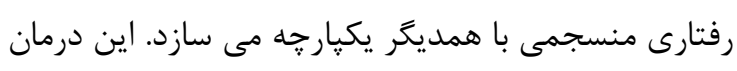

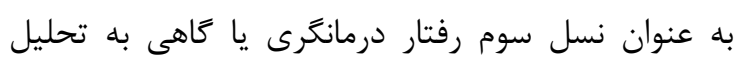

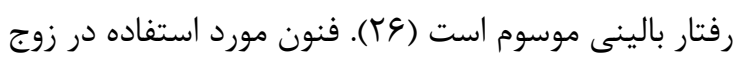

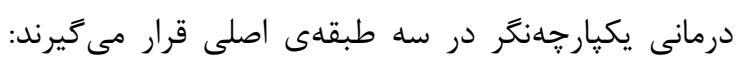

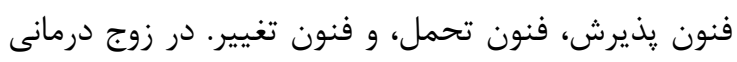

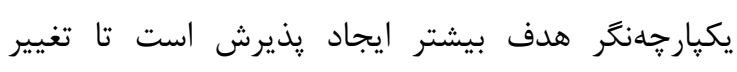

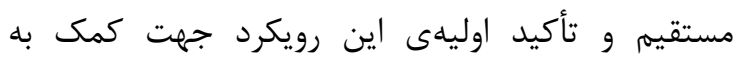

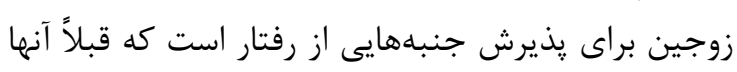

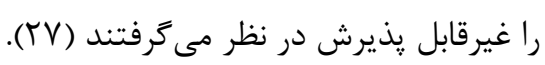

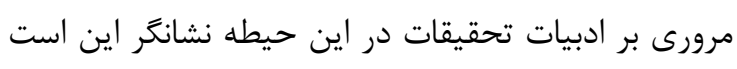

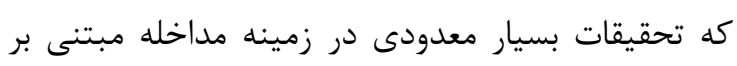

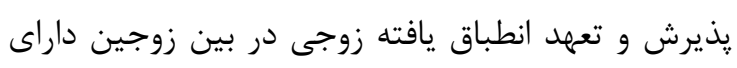

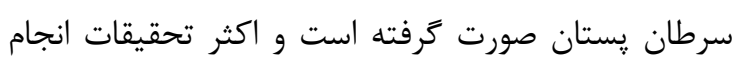

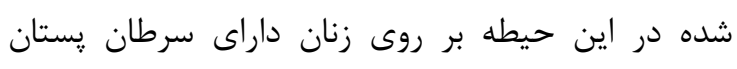

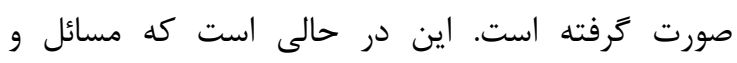
مشكلات درونى بين زوجين، تعارضها و ارتبن ارتباطات آنها آنها

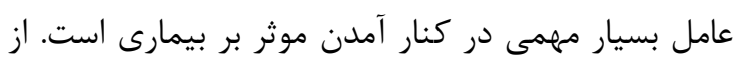

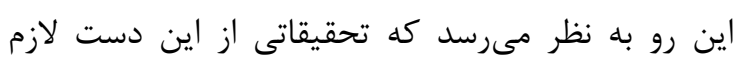

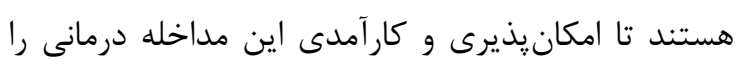

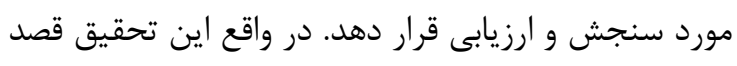

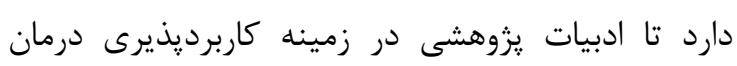

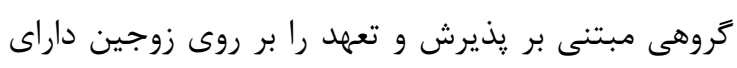

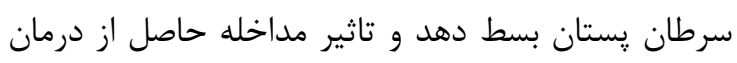


يكيار جهنكر و درمان مبتنى بر يذيرش و تعهد انطباق يافته

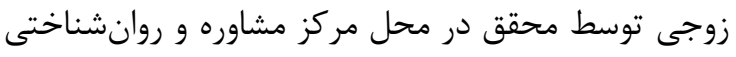

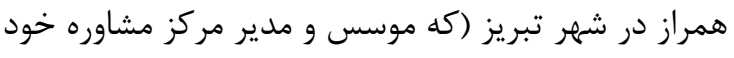

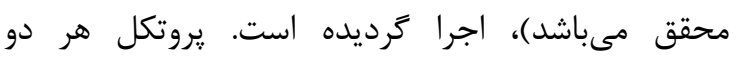

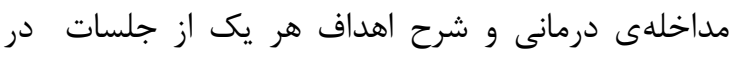

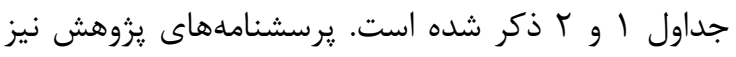

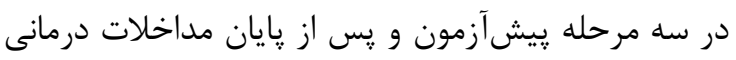

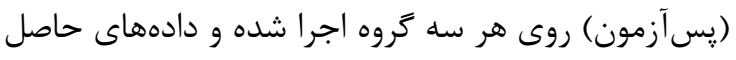

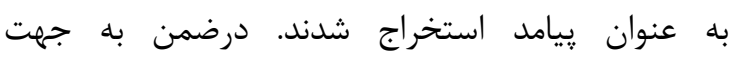

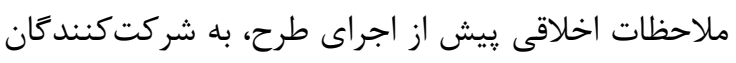

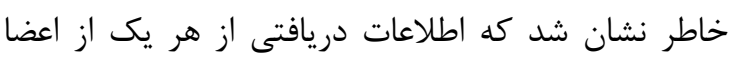

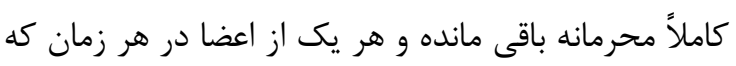

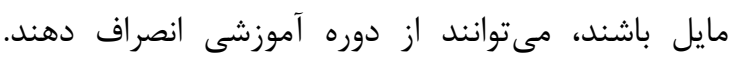

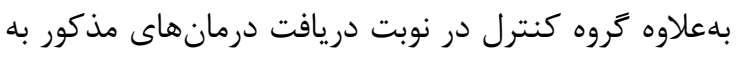

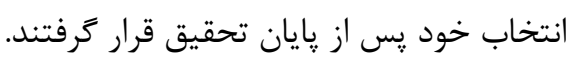
تجزيه و تحليل دادهها با استفاده از تحليل كواريانس (ANCOVA)

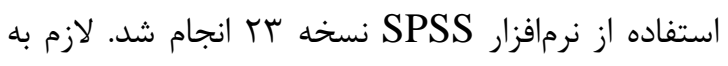

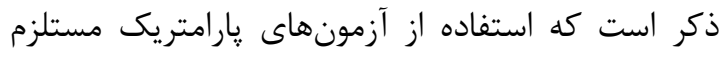

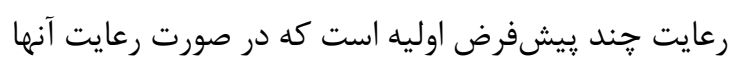

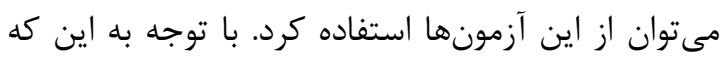

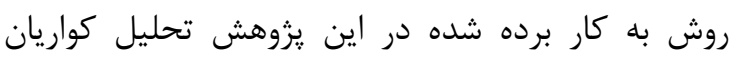

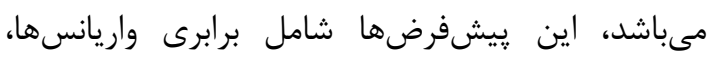

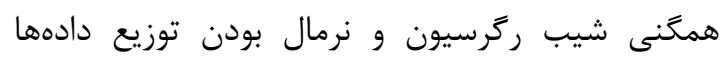

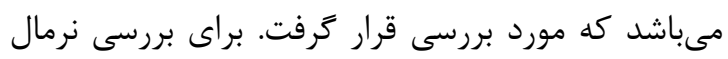

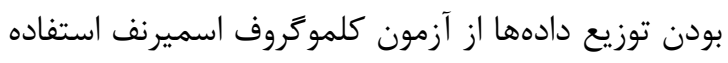

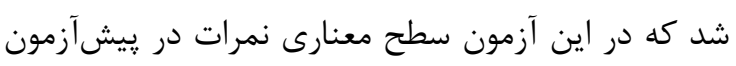

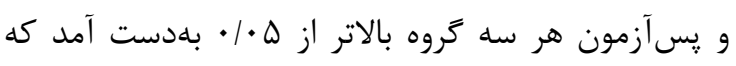

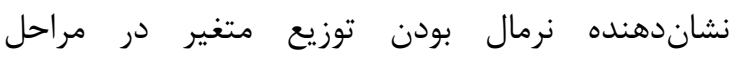
اندازهيرى و به تفكيك تروه مى باشد. جهت بررسى مفروضه برابرى واريانس گرووهها از آزمون

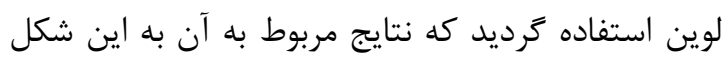

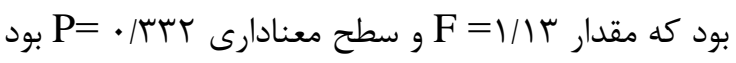

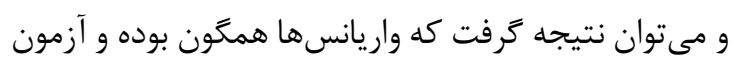
تحليل كوواريانس مقدور است. همجنين براى بررسى فقدان تعامل بين گَروهها و نمرات

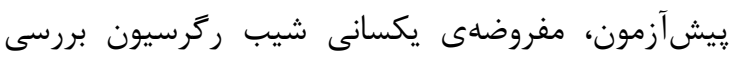

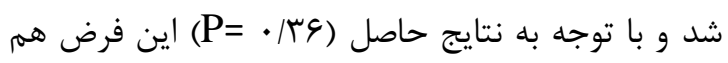

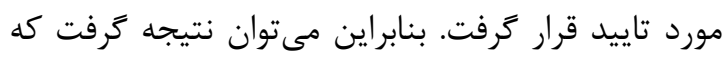

اطلاعات مربوط به آزمودنىها، عدم اجبار براى واداشتن

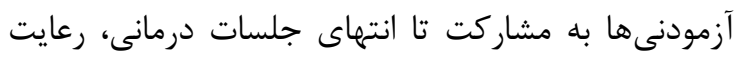

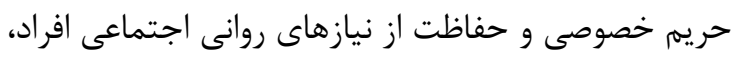

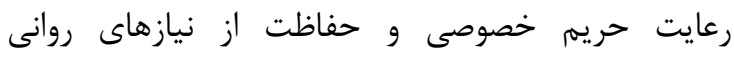

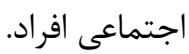
اين تحقيق، در جلسه اعץ كميته منطقهاى اخلاق مورخه 9V/.9/19 IR.IAU.k.REC.1397.28 مصوبه كميته اخلاق دانشعاه آزاد واحد كرج مورد تاييد قرار كرفته است.

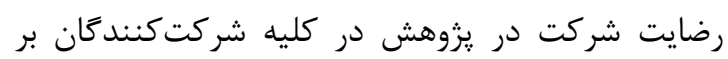

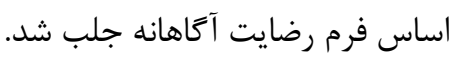
9ه بنظور اجراى تحقيق در مرحله اول در مرداد ماه

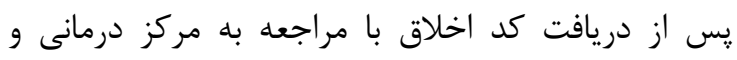

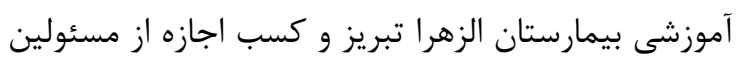

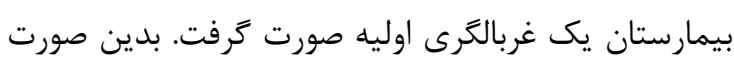

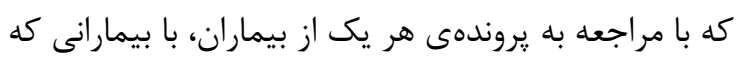

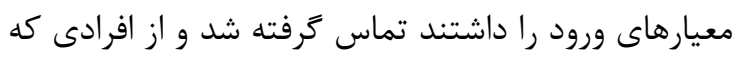

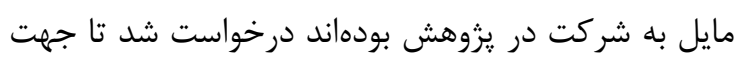

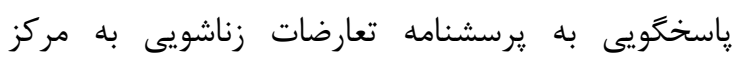
مشاوره و خدماتى روانشناختى همراز واقع در شهر تبريز

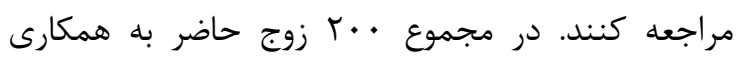

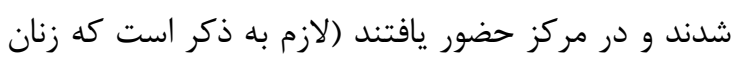

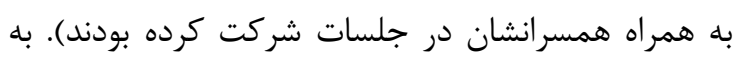

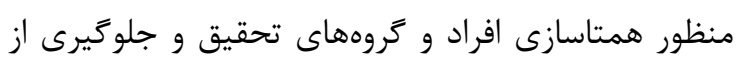

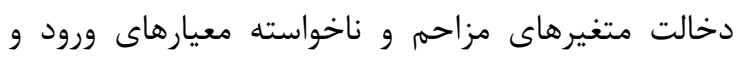

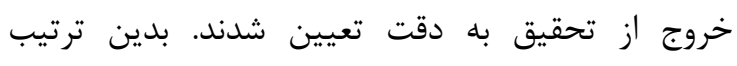

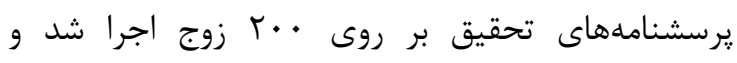

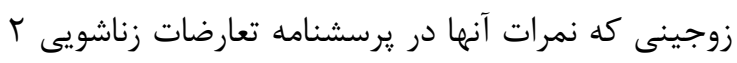

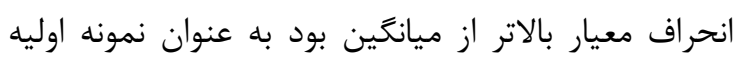
انتخاب شدند. هأ زوجى كه بالاترين نمره را كرفته بودند،

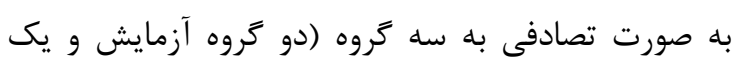

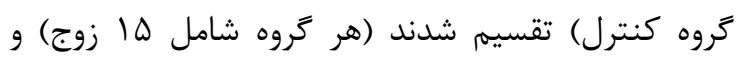

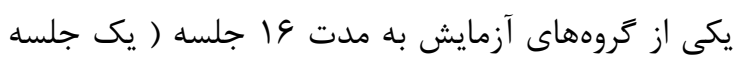

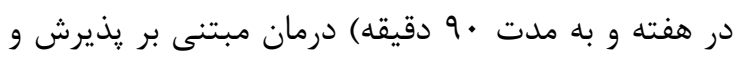

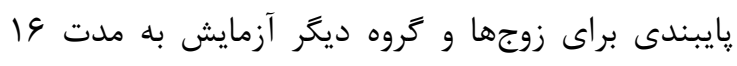
جلسه (يك جلسه در هفته به مدت ·و بو دقيقه) زورج درمانى يكيارجهنگ

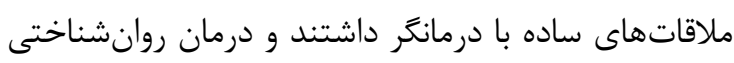

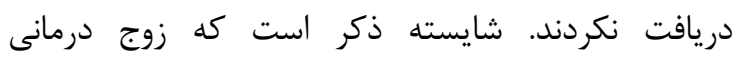




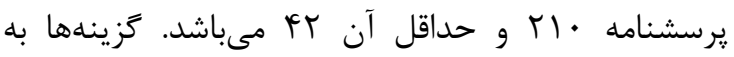

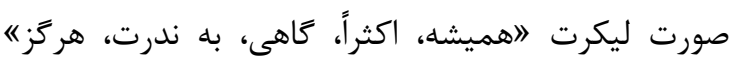
بيان مىشوند. ضريب آلفاى كرونباخ براى كل مقياس التراس

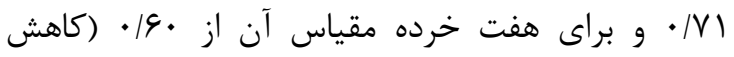

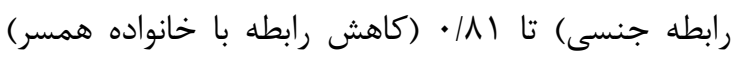

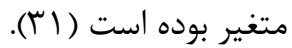

\section{درمان مبتنى بر يذيرش و تعهد براى زوجها: اين}

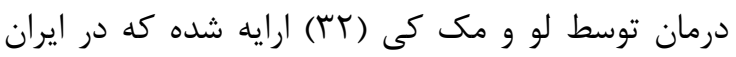

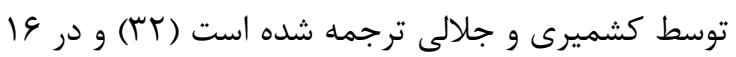

جلسه •و دقيقهاى به شرح زير اجرا مىشود (جدول ().
بين گروهها و ييشآزمون تعاملى وجود ندارد. با توجه به اينكه هر سه مفروضه براى آزمون تحليل كوواريانس برقرار بود مىتوان كفت كه استفاده از تحليل كوواريانس براى إنى تهايل

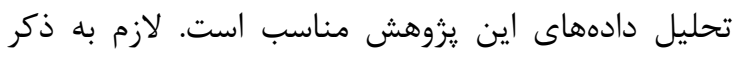

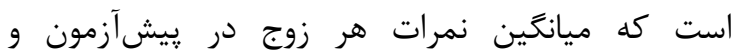
يس آزمون تحليل شده است.

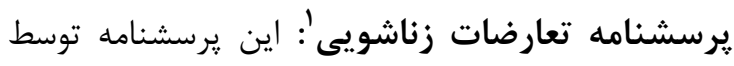

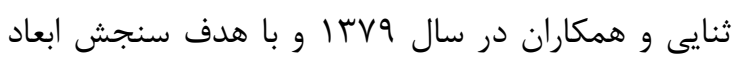

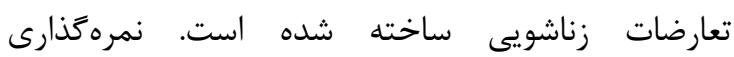
يرسشنامه به صورت طيف ليكرت ينج درجهاى مىباشد.

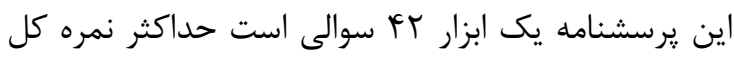

جدول ا: يروتكل درمان مبتنى بر يذيرش و تعهد

جلسه +9 دقيقهاى با \&| جلسه به شرح زير اجرا شده است:

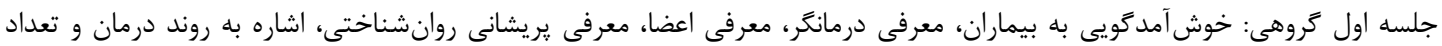
جلسات

جلسه دوم و سوم كروهى: شناسايى طرحوارهها و برانكَيزانندهاى آنها آنها

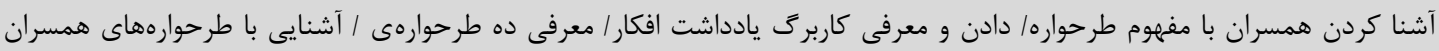

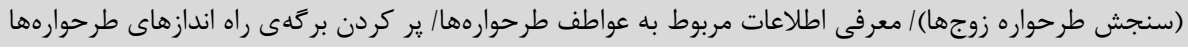

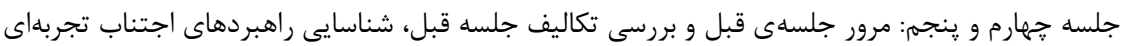

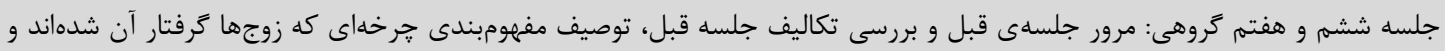

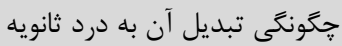

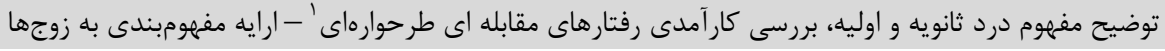

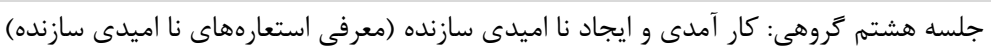
جلسه نهم كروهى: روشن سازى ارزشها:

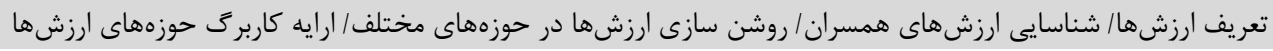

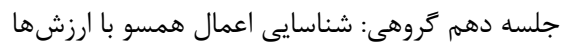

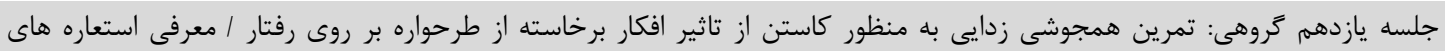

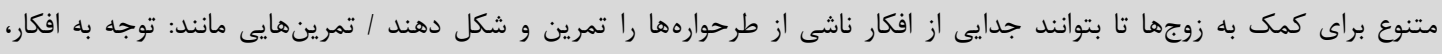

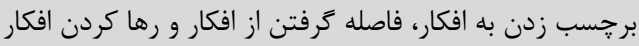

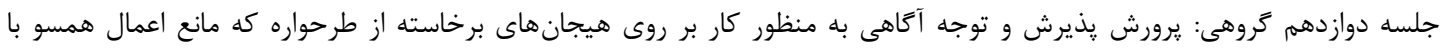

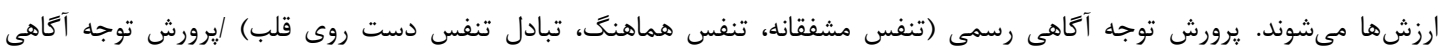

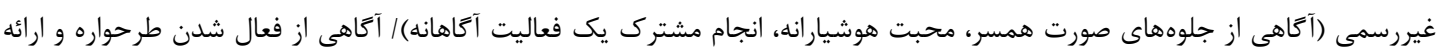

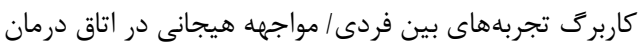

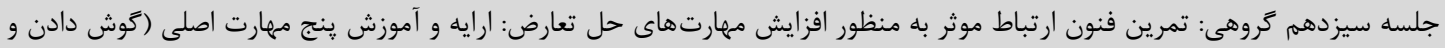
تصديق كردن، ابراز وجود، مذاكره، قدردانى

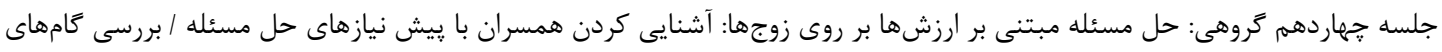

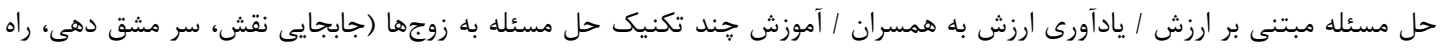
حل حاى مشاركتى)

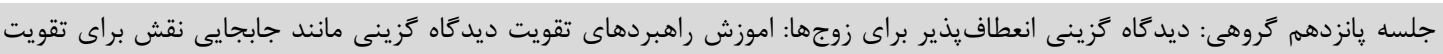

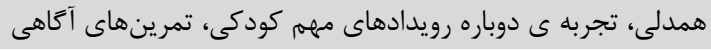

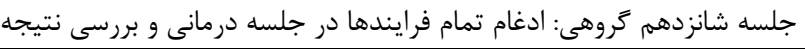

\footnotetext{
${ }^{1}$ Marital Conflict Questionnaire

${ }^{2}$ Schema coping behaviors (SCB)
} 
يكيارجهنكر بر اساس راهنماى كتاب يذيرش و تغيير در زوج درمانى اثر جيكوبسن و كريستنسن (צا) در غالب عاجلسه اجرا شد (rr) (جدول كر).

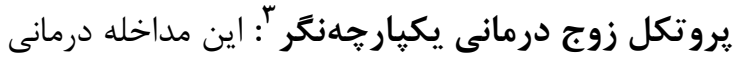

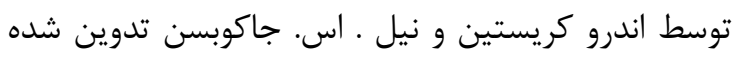

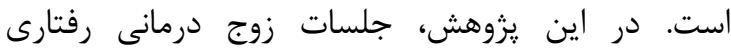

جدول r: يروتكل زوج درمانى يكيار جهنكگ

\begin{tabular}{|c|c|}
\hline شرح فرايند ارزيابى زوجين، بررسى و ارزيابى مشكلات وارزيابى تاريخجه ارتباطى زوجين & جلسه اول \\
\hline ارزيابى ميزان آشفتكى و تعهد زوجين، اريابى محتواى تعارض زوجين & 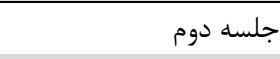 \\
\hline سازماندهى مجدد مشكلات زوجين به شكل تمهاى قابل فهمتر & 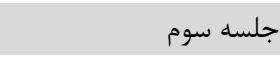 \\
\hline توضيح منطق درمان، ضوابط و قاعدهمندى درمان و مسائلى كه مراجعين بايد رعايت كنند شرح داده مىشود & جلسه جهارم \\
\hline فرمولبندى مجدد مشكلات و رفتارهاى منفى همسران، تاكيد بر ميزان درد و رنجى كه هر يك از زوجين تجربه مى كنند & جلسه پنجم \\
\hline ايجاد افشاكرى نرم در برابر افشاكرى سخت & جلسه ششم \\
\hline آموزش بخشى از مهارتهاى ارتباطى كه بر آموزش همدلى از طريق كوش دادن فعال متمركز است & جلسه هفتم \\
\hline هدف كلى ايجاد يذيرش از طريق انفصال يكيارجه & جلسه هشتم تا دهم \\
\hline برجسته سازى جنبه هاى مثبت رفتار هاى منفى براى ايجاد تحمل & 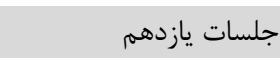 \\
\hline 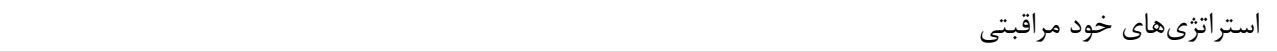 & 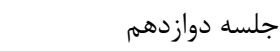 \\
\hline ليست رفتارهايى را كه باعث افزايش رضايت زناشويى در طرف مقابل مىشود & جلسه سيزدهم تا يانزدهم \\
\hline آموزش مهارت هاى ارتباطى و آموزش مهارتهاى حل مساله & 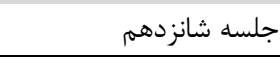 \\
\hline
\end{tabular}

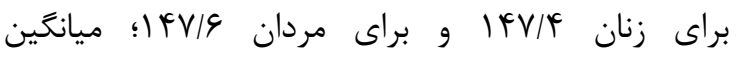

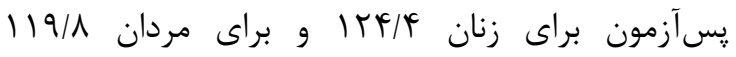

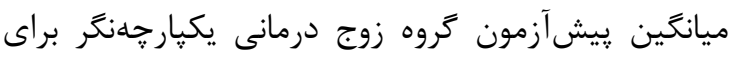

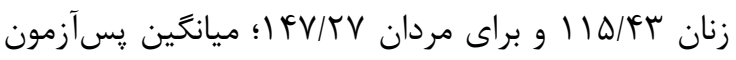

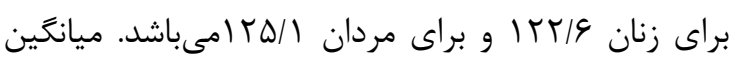

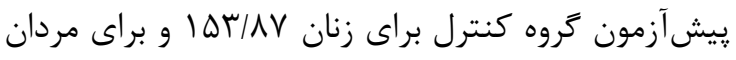

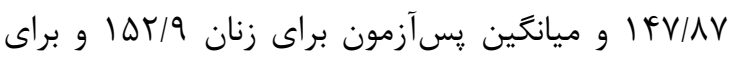

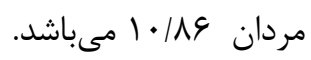
تحليل استنباطى دادهها: درمان مبتنى بر ريذيرش و و واند

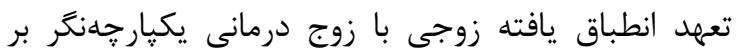

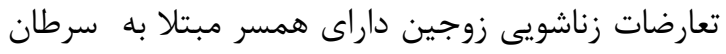

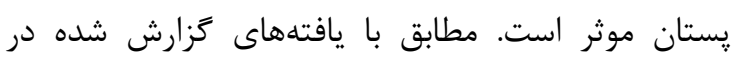
جدول ه مشخص است كه بين ميانخين باقى مانده نمرات

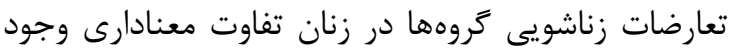

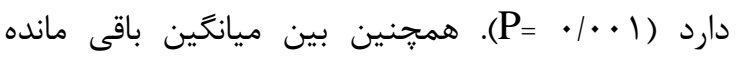
نمرات تعارضات زناشويى كروهها در بين مردان تفانين

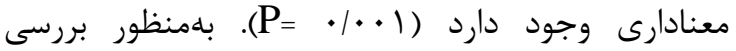
جزئىتر اين تفاوت از آزمون تعقيبى بن فرنى استفاده شد إداء

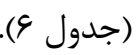
مطابق با يافتهاى تزارش شده در جدول (9) بين ميانكين نمرات يسآزمون تعارضات زناشويى كروه كنترل

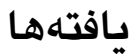
در اين قسمت از يزوهش نتايج حاصل از دادههاى آمارى و

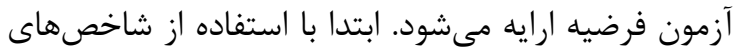

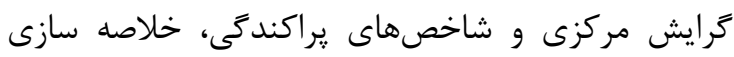
دادهها صورت مى گيرد و در بررسى فرضيه يز يزوهش ابتدا به نتايج آزمون يِيش فرضهاى آزمون تحليل كوواريانس

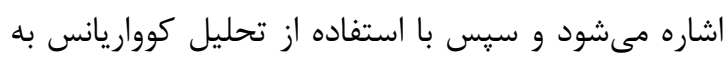
تاييد يا رد فرض صفر مى يردازيم. توصيف دادهها: همانَّونه كه در جدول ب مشاهده

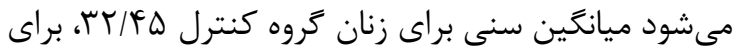

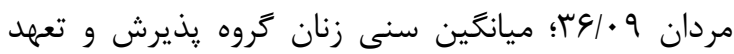

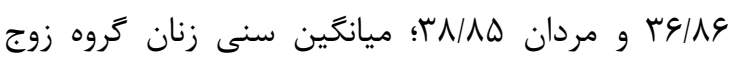

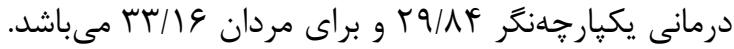
فراوانى سطح تحصيلات براى هر سه كروه بـانه تفكيك مراني جنسيت در جدول ب قابل مشاهده است.

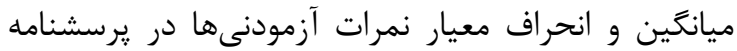

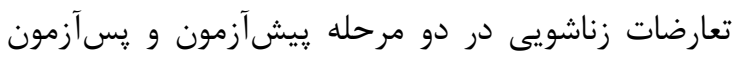

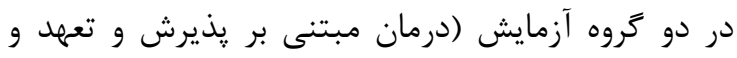

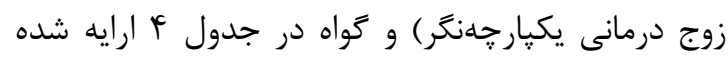

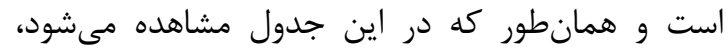

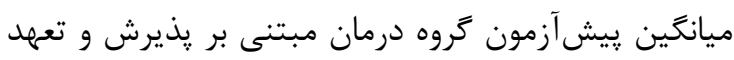

\footnotetext{
${ }^{3}$ Integrative behavior couple therapy (IBCT)
} 
زناشويى كروه كنترل با كروه يذيرش و تعهد در مردان

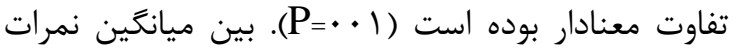

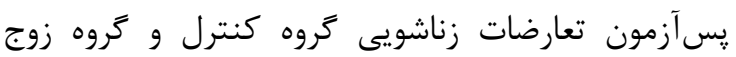

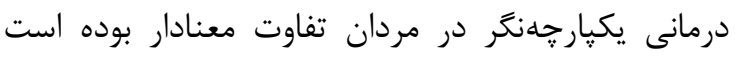

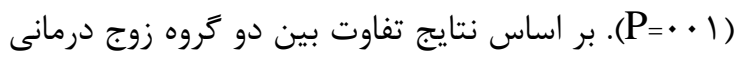

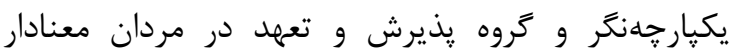
نمىباشد (P=• P (P).
با كروه يذيرش و تعهد در زنان تفاوت معنادار بوده است P=・1)

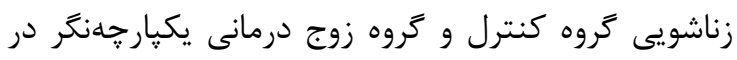

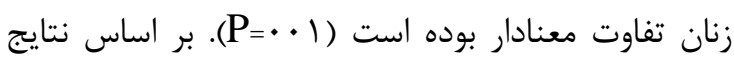

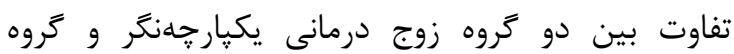

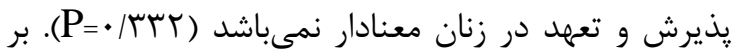

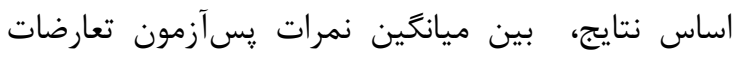

جدول ז: مشخصات دمو

\begin{tabular}{|c|c|c|c|c|c|c|c|}
\hline \multicolumn{5}{|c|}{ تحصيلات } & \multirow{2}{*}{ ميانَين سنى } & \multirow{2}{*}{ جنسيت } & \multirow{2}{*}{ كروه } \\
\hline فوق ليسانس & ليسانس & فوق دييله & ديبلم & زير دييلم & & & \\
\hline \multirow[t]{2}{*}{. } & V & 9 & $r$ & . & $r 4 / .9$ & مردان & \multirow{2}{*}{ 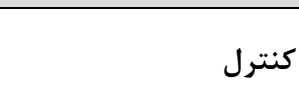 } \\
\hline & r & r & v & f & $r T / F \Delta$ & 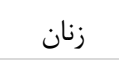 & \\
\hline r & v & q & $r$ & . & TN/AD & مردان & \multirow{2}{*}{ يذيرش و تعهد } \\
\hline . & r & f & 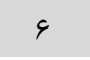 & r & एG/A૬ & 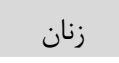 & \\
\hline \multirow[t]{2}{*}{. } & \multirow[t]{2}{*}{ IT } & \multirow[t]{2}{*}{. } & \multirow[t]{2}{*}{ ir } & \multirow[t]{2}{*}{4} & (1) & مردان & \multirow{2}{*}{ زوج درمانى يكيارجهنگر } \\
\hline & & & & & $r q / \Lambda r$ & زنان & \\
\hline
\end{tabular}

فراوانى سطح تحصيلات براى هر سه گروه در جدول ب قابل مشاهده است.

جدول F: ميانكين و انحراف معيار و بررسى نرمال بودن نمرات تعارضات زناشويى كَروهها در بيش آزمون و يس آزمون

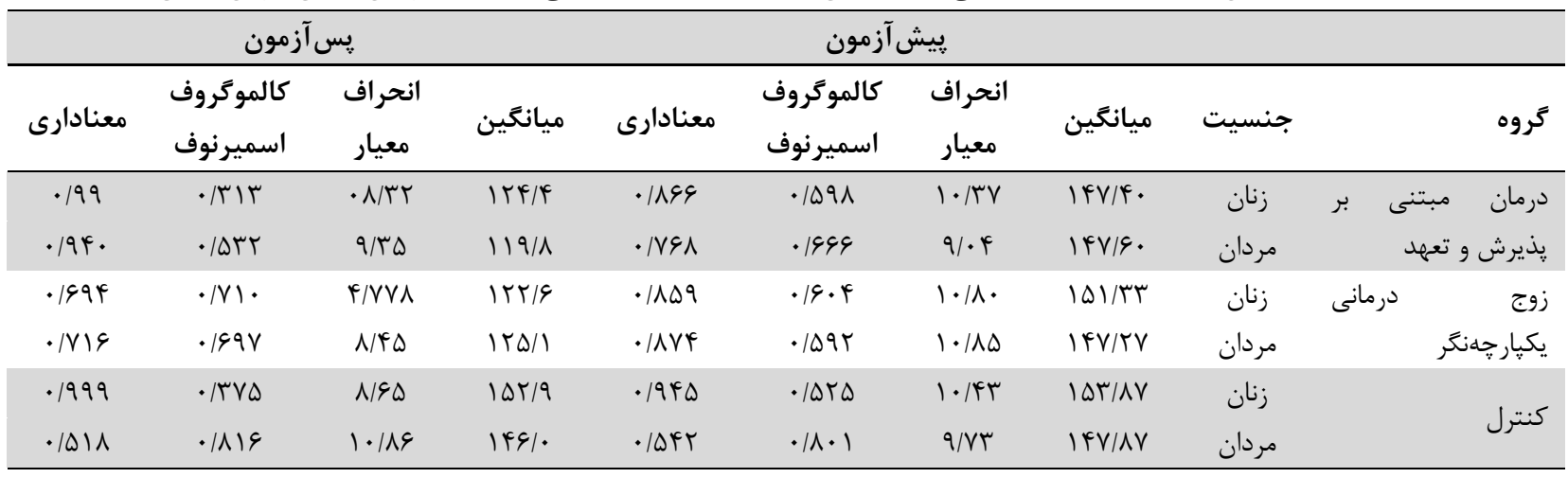

جدول ه: نتايج تحليل كوواريانس براى بررسى تاثير عضويت كروهى بر ميزان نمرات تعارضات زناشويى

\begin{tabular}{|c|c|c|c|c|c|c|c|}
\hline ضريب اتا & سطنادارى & $\mathbf{F}$ & مجانگين & آزادى درجه & مجذمورات & منابع & جنسيت \\
\hline (rq & $\cdot 1 \cdot \cdot 1$ & TE/QTV & $91 N / \Delta \cdot V$ & 1 & $91 \wedge / \Delta \cdot V$ & يِيشآزمون & \\
\hline \multirow[t]{2}{*}{ - /ArA } & $\cdot 1 \cdot \cdot 1$ & $1 \cdot \varepsilon / \pi \Delta \Lambda$ & rGAT/GDA & r & $V K G \Delta / r / D$ & عضويت گروهى & زنان \\
\hline & & & TY/GTD & (i) & $1 F \mid 9 / 949$ & خطا & \\
\hline$\cdot /\{\wedge \Lambda$ & $.1 \cdot .1$ & $r q / \cdot r V$ & $\mid 199 / 91 \vee$ & 1 & $1191 / 91 V$ & بِيش آزمون & \\
\hline \multirow[t]{2}{*}{./VTA } & $.1 \cdot .1$ & $\Delta \vee / \Lambda \& \mid$ & $r \Lambda \cdot r / q \cdot r$ & r & $\Delta G \cdot q / \Lambda / F$ & عضويت تروهى & مردان \\
\hline & & & FN/FVV & (i) & $19 \wedge \mathrm{V} / 0 \mathrm{Fq}$ & خطا & \\
\hline
\end{tabular}


جدول \&: آزمون تعقيبى بن فرنى براى مقايسه اثربخشى سه تروه در تعارضات زناشويى

\begin{tabular}{|c|c|c|c|c|c|}
\hline سطح معنى دارى & خطاى انحراف معيار & اختلاف ميانكين (I-J) & كروه (J) & تروه (I) & جنسيت \\
\hline$\cdot 1 \cdot \cdot 1$ & $T / T r$. & TQ/\&GT & كروه يذيرش و تعهد & كروه كنترل & \multirow{3}{*}{ زنان } \\
\hline$\cdot 1 \cdot \cdot 1$ & $r / 19$. & $r q / r \cdot q$ & 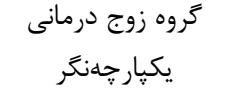 & كروه كنترل & \\
\hline אזr/ן & $r / I V D$ & T/DFG & 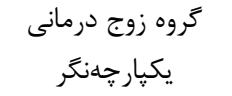 & كروه يذيرش و تعهد & \\
\hline$\cdot 1 \cdot \cdot 1$ & T/QFT & $r \Delta / 9 \Delta r$ & كروه يذيرش و تعهد & تروه كنترل & \multirow{3}{*}{ مردان } \\
\hline$\cdot 1 \cdot \cdot 1$ & T/DFT & $r \cdot / 4 q$. & يَروه زوج درمانى & تروه كنترل & \\
\hline.$/ 11$ & T/DFT & $-Q / F q r$ & 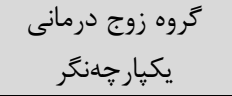 & كروه يذيرش و تعهد & \\
\hline
\end{tabular}

تعهد در كاهش علايم افسردگى و ارتقا كيفيت زندگى در

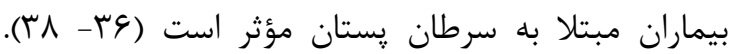

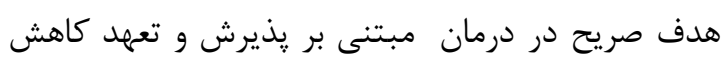

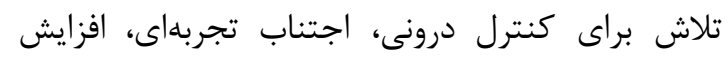

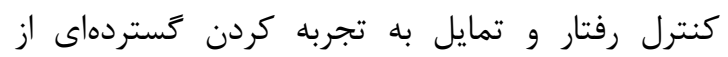

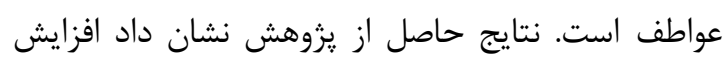
كنترل رفتار و تمايل به تجربه كردن كستردهاى از

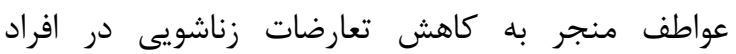
سرطانى مى گردد. درمان مبتنى بر يذيرش و تعهد انطباق

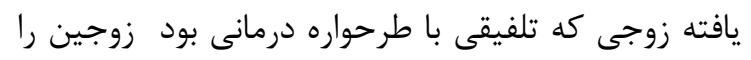
به مواجهه با درد برخاسته از طرحواره به منظور زيستن

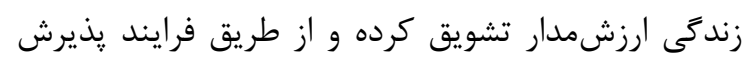

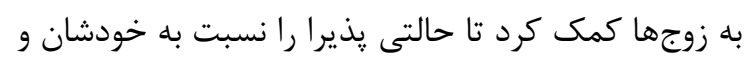
همسرشان و مشكل جسمى يیش آمده (سرطان پِيستان)،

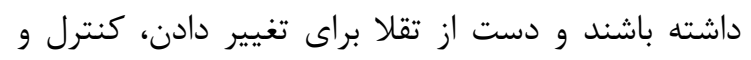

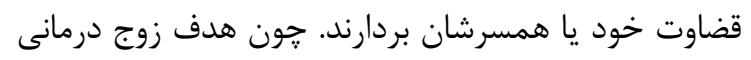

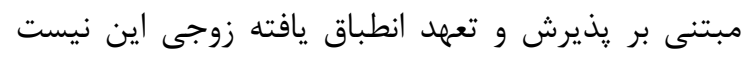

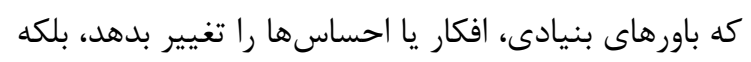

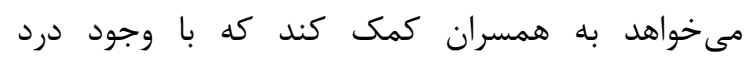

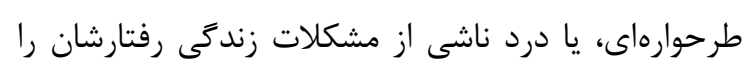

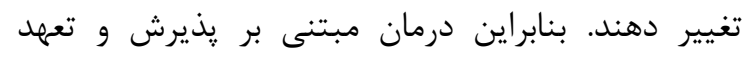

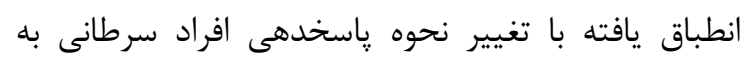

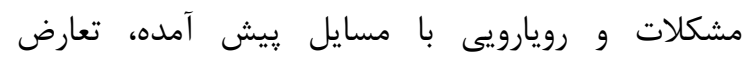

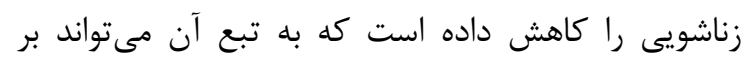

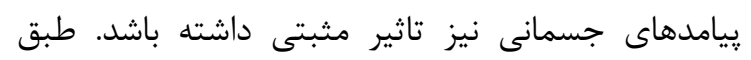
يزوهشهاى انجام شده عدم رضايت زناشويى در بيماران داراى سرطان يستان با عوامل روانشناختى ديخرى نظير

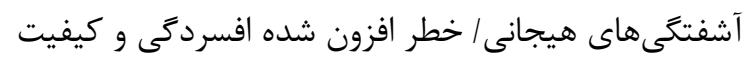

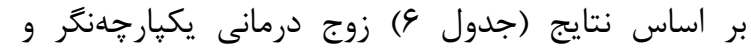
درمان يذيرش و تعهد بر كاهش تعارضات زناشويى در

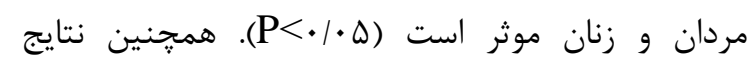

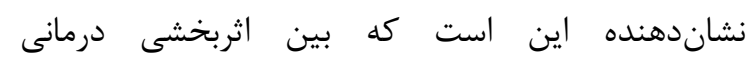

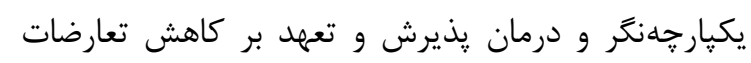

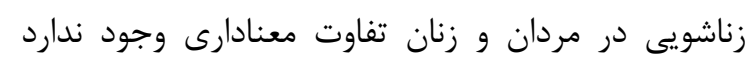

$(\mathrm{P}>\cdot / \cdot \Delta)$

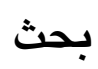

هدف يزوهش حاضر مقايسه اثربخشى درمان مبتنى بر

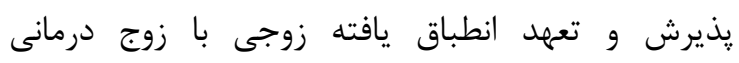

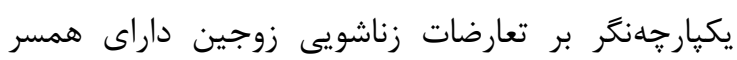

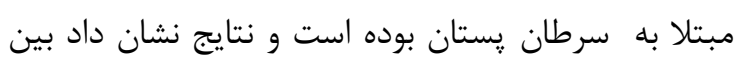

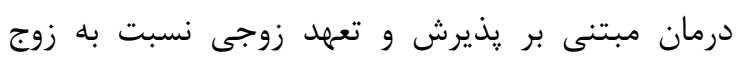

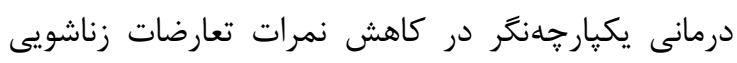

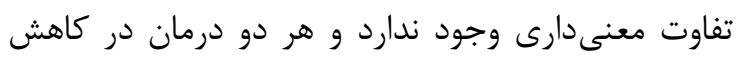

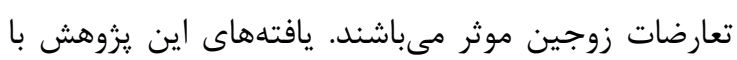

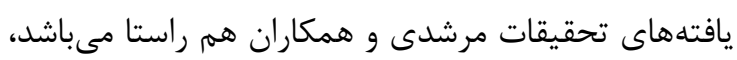

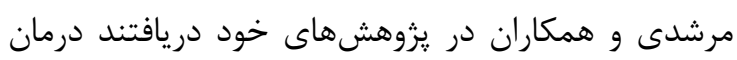

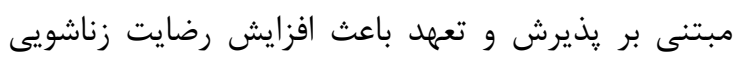

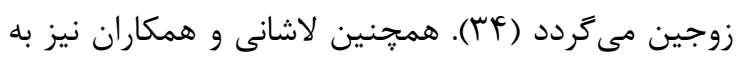
اين نتيجه رسيدند كه مداخله مبتنى بر يذيرش و تعهد بر

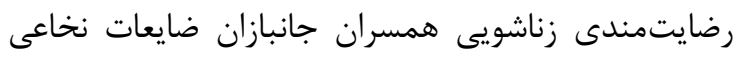

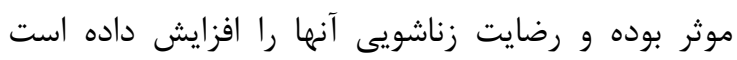

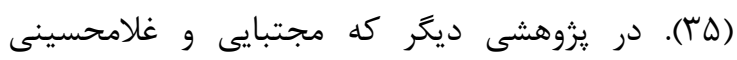

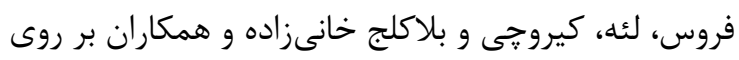
زنان مبتلا به سرطان يستان با نشانههاى افسردگى انجام

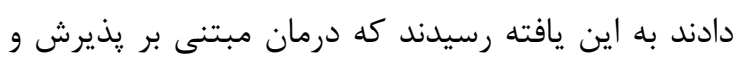


تجارب مشترك، ارتباط عاطفى صميمانه، ذهن آكاهى و در نتيجه كاهش تعارضات زناشويى زوجين كردد.

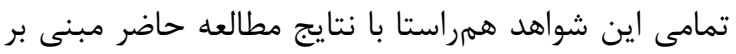

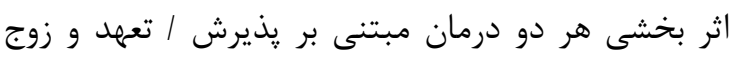

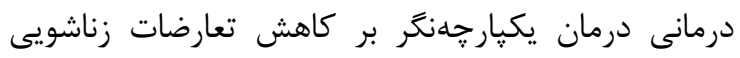
مىباشد. در كل مطالعات مختلف نشان مىدهد كه انواع

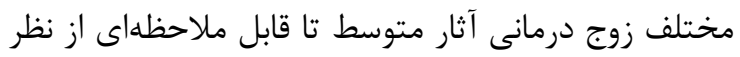

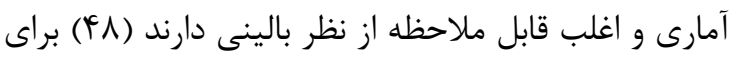

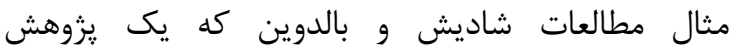

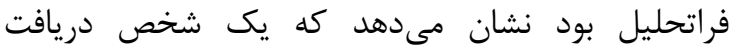

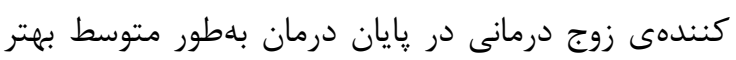

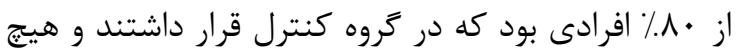

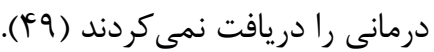

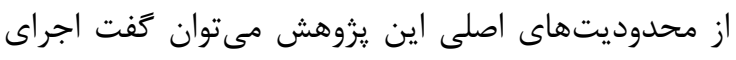

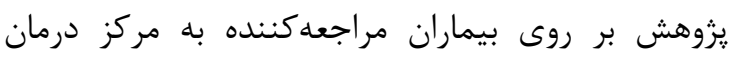
بيمارستان الزهراى تبريز تعميم نتايج را با با محدوديت

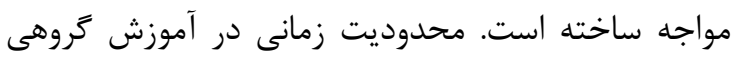

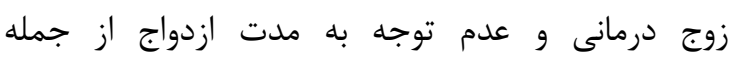

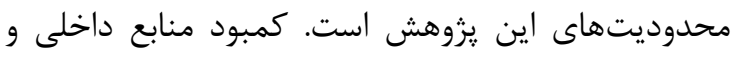

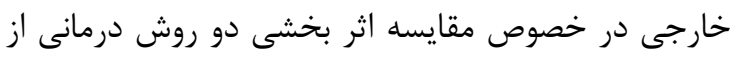

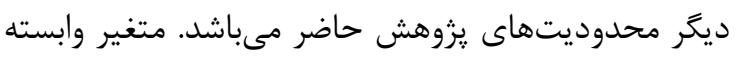
از طريق يرسشنامهاى خود سنجى مورد اندازهيرى قرار كرفته است كه ممكن است آزمودنى با سوكيرى به به آن آن

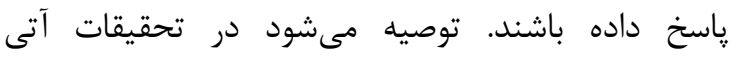

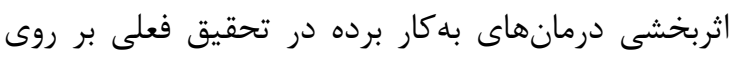

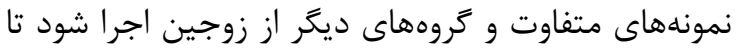

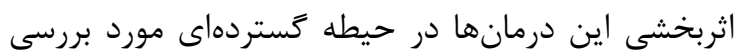

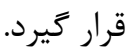
در ادامه توصيه مىشود از ساير ابزارهاى سنجشى نظير يرسشنامههاى مبتنى بر سنجش توسط همسر، والدين و

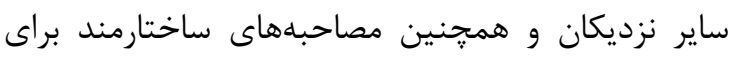
سنجش متغيرهاى وابسته تحقيق استفاده شود. آثار بلند مدت درمانهاى بهكار برده شده در اين تحقيق مورد

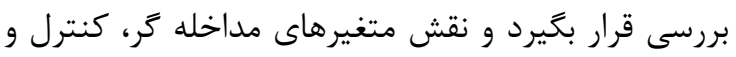

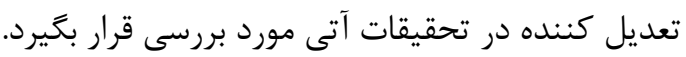

\section{نتيجهكگيرى}

نتيجه تحقيق فعلى نشان مىدهد كه درمان مبتنى بر

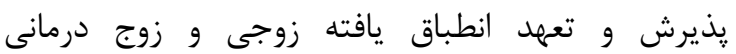

زندگى مرتبط هست و اين عوامل به نويه خود ِيشيشينى

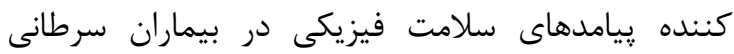

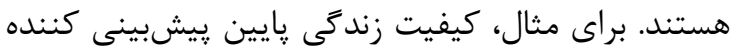

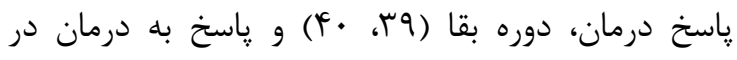

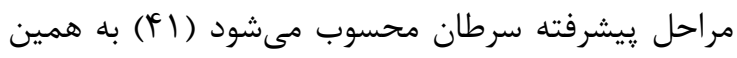

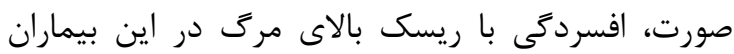
ارتباط دارد (FT) (F).

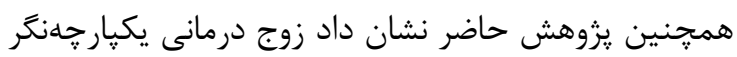
بر كاهش تعارضات زناشويى زنان مبتلا به بيمارى يستان

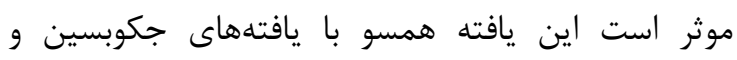

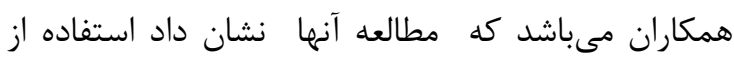

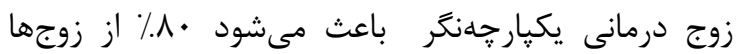
بهبود قابل ملاحظه از نظر بالينى داشته باشند (بآل).

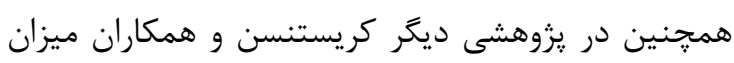

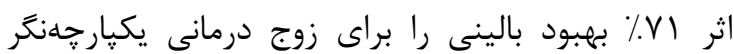

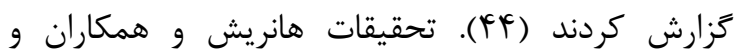

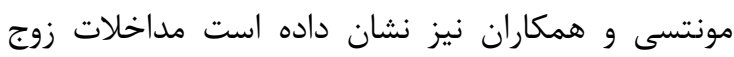

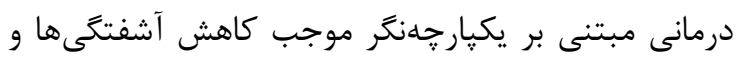
بهبودى رضايت از رابطه زناشويى و ارتباطات زوجين مبتلا به بيمارى سرطان مى

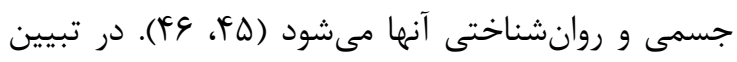

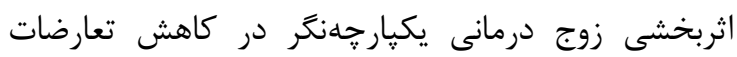

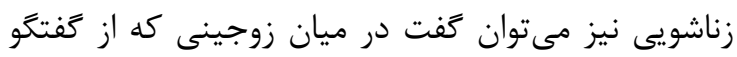

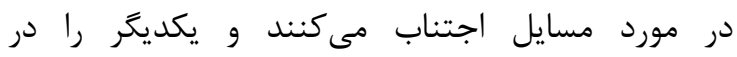

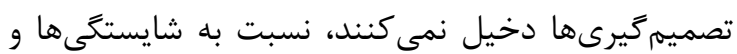
توانايىهاى يكديكر دجار مشكل شده و براى تصميمات

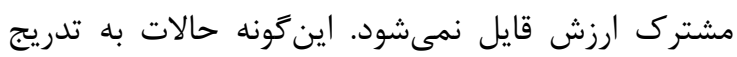
منجر به كاهش اعتماد به خود و طرف مقابل ورئ ور در نتيجه ايجاد اضطراب مىشود زمانى كه زوجين دجار تعارض

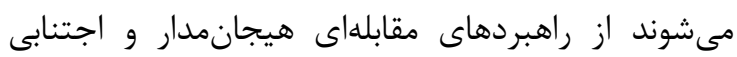

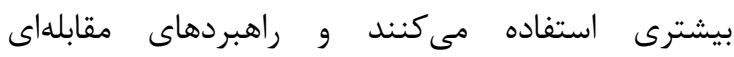

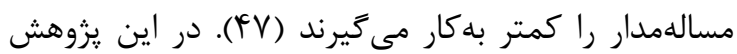

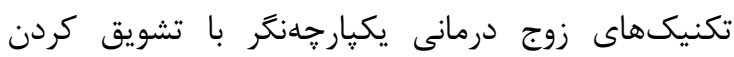
زوجين به استفاده از در راهبردهاى مقابلهاى مسالهمدار

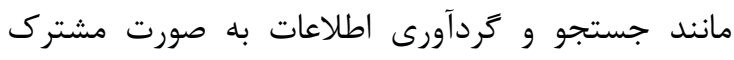
براى حل مساله، كمك به يكديگر براى انجام كارها،

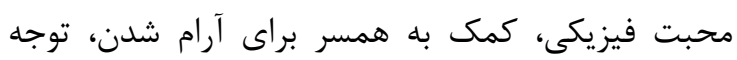

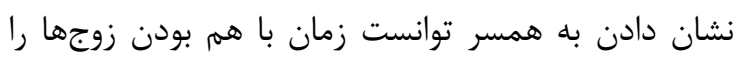

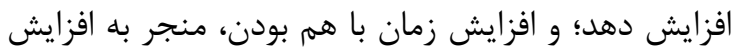


باشد. زيرا به درمانگران كمك مى كند طرحوارههايى را كه

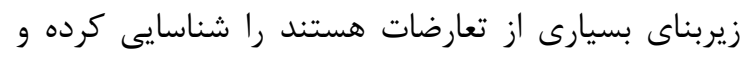
تكنيكهاى يذيرش و مواجهه هيجانى را براى تسهيل

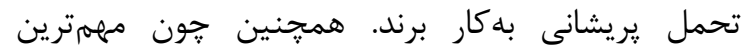
استراتثىهايى مانند ايجاد يذيرش از طيق همدلانه، ايجاد تحمل از طريق تمرين رفتار در منزل، افزايش تحمل از

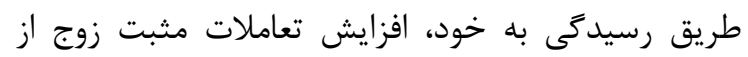

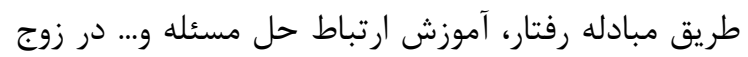

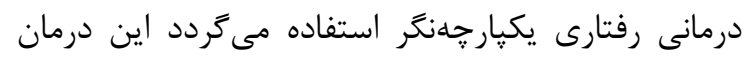

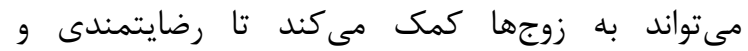
سازعاريشان افزايش يابد.

$$
\begin{aligned}
& \text { تعارض منافع } \\
& \text { نويسندگان اعلام مىدارند كه هيج تعارض منافعى در } \\
& \text { يزوهش حاضر وجود ندارد. }
\end{aligned}
$$

\section{References}

1. International Agency for Research on Cancer. Globocan: estimated cancer incidence, mortality and prevalence worldwide in. 2012.

2. Alacacioglu A, Ulger E, Varol U, Yildiz I, Salman T, Bayoglu V, Dirican A, Demir L, Akyol M, Yildiz Y, Tarhan MO. Depression, anxiety and sexual satisfaction in breast cancer patients and their partners-izmir oncology group study. Asian Pac J Cancer Prev. 2014; 15(24):10631-6.

3. Taleghani F, Yekta ZP, Nasrabadi AN. Coping with breast cancer in newly diagnosed Iranian women. Journal of Advanced nursing. 2006; 54(3):265-72.

4. Boehmke MM, Dickerson SS. The diagnosis of breast cancer: transition from health to illness. InOncology nursing forum. 2006; 33(6):1-8.

5. Shapiro SL, Lopez AM, Schwartz GE, Bootzin R, Figueredo AJ, Braden CJ, Kurker SF. Quality of life and breast cancer: relationship to psychosocial variables. Journal of clinical psychology. 2001; 57(4): 501-19.

6. Ming VM. Psychological predictors of marital adjustment in breast cancer patients. Psychology, health \& medicine. 2002; 7(1): 3751.

7. Dalton III WT, Nelson DV, Brobst JB, Lindsay JE, Friedman LC. Psychosocial variables

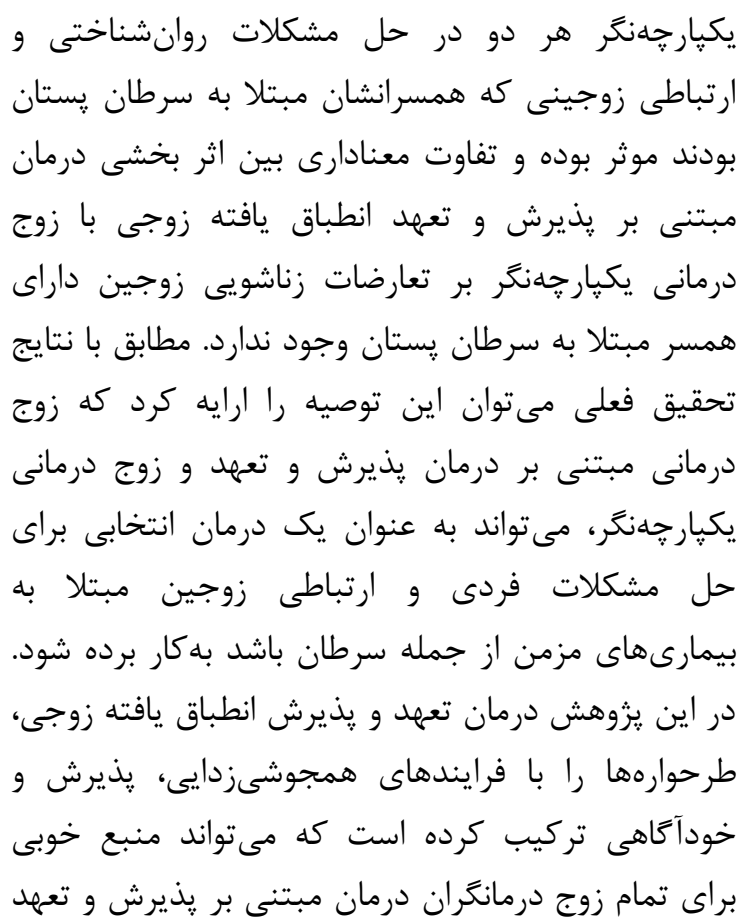

associated with husbands' adjustment three months following wives' diagnosis of breast cancer. Journal of Cancer Education. 2007; 22(4): 245-9.

8. Coates AS, Hürny C, Peterson HF, Bernhard J, Castiglione-Gertsch M, Gelber RD, Goldhirsch A, International Breast Cancer Study Group. Quality-of-life scores predict outcome in metastatic but not early breast cancer. Journal of Clinical Oncology. 2000; 18(22): 3768-74.

9. Montazeri A. Health-related quality of life in breast cancer patients: a bibliographic review of the literature from 1974 to 2007. Journal of experimental \& clinical cancer research. 2008;27(1):32.

10. Goodwin JS, Zhang DD, Ostir GV. Effect of depression on diagnosis, treatment, and survival of older women with breast cancer. Journal of the American Geriatrics Society. 2004; 52(1):106-11.

11. Kornblith AB, Herndon JE, Weiss RB, Zhang C, Zuckerman EL, Rosenberg S, Mertz M, Payne D, Jane Massie M, Holland JF, Wingate P. Long term adjustment of survivors of early stage breast carcinoma, 20 years after adjuvant chemotherapy. Cancer: Interdisciplinary International Journal of the American Cancer Society. 2003 Aug 15;98(4):679-89. 
12. Baucom DH, Kirby JS, Pukay Martin ND, Porter LS, Fredman SJ, Gremore TM, Keefe FJ, Atkins D. Men's psychological functioning in the context of women's breast cancer. Journal of marital and family therapy. 2012 Apr;38(2):317-29.

13. Weihs KL, Enright TM, Simmens SJ. Close relationships and emotional processing predict decreased mortality in women with breast cancer: preliminary evidence. Psychosomatic medicine. 2008; 70(1): 117-24.

14. Sbitti Y, Kadiri H, Essaidi I, Fadoukhair Z, Kharmoun S, Slimani K, Ismaili N, Ichou M, Errihani H. Breast cancer treatment and sexual dysfunction: Moroccan women's perception. BMC women's health. 2011; 11(1): 29.

15. Ussher JM, Perz J, Gilbert E. Information needs associated with changes to sexual well being after breast cancer. Journal of advanced nursing. 2013 Feb;69(2):327-37.

16. Navabinejad S. Marriage counseling and family. Tehran, Iran: Anjomanolia va Morbian Publication; 2006. [In Persian].

17. Day MA, Halpin J, Thorn BE. An empirical examination of the role of common factors of therapy during a mindfulness-based cognitive therapy intervention for headache pain. The Clinical journal of pain. 2016; 32(5): 420-7.

18. Dahl J, Wilson KG, Nilsson A. Acceptance and commitment therapy and the treatment of persons at risk for long-term disability resulting from stress and pain symptoms: A preliminary randomized trial. Behavior therapy. 2004; 35(4):785-801.

19. Litt MD, Kadden RM, Cooney NL, Kabela E. Coping skills and treatment outcomes in cognitive-behavioral and interactional group therapy for alcoholism. Journal of consulting and clinical psychology. 2003;71(1):118.

20. Kashdan TB, Rottenberg J. Psychological flexibility as a fundamental aspect of health. Clinical psychology review. 2010; 30(7): 86578.

21. Robinson P, Wicksell RK, Olsson GL. ACT with chronic pain patients. InA practical guide to acceptance and commitment therapy 2004; 315-345.

22. Gaudiano BA, Herbert JD. Acute treatment of inpatients with psychotic symptoms using Acceptance and Commitment Therapy: Pilot results. Behaviour research and therapy. 2006; 44(3): 415-37.

23. Mitchell AJ, Chan M, Bhatti H, Halton M, Grassi L, Johansen C, Meader N. Prevalence of depression, anxiety, and adjustment disorder in oncological, haematological, and palliative-care settings: a meta-analysis of 94 interview-based studies. The lancet oncology. 2011; 12(2): 16074.

24. Paez-Blarrina M, Luciano C, GutiérrezMartínez O, Valdivia S, Ortega J, RodríguezValverde M. The role of values with personal examples in altering the functions of pain: Comparison between acceptance-based and cognitive-control-based protocols. Behaviour Research and Therapy. 2008; 46(1): 84-97.

25. Amanelahi A, Heydarianfar N, Khojastehmehr R, Imani M. Effectiveness of acceptance and commitment therapy (ACT) in the treatment of distressed couples. Biannual Journal of Applied Counseling. 2014; 4(1): 10319.

26. Jacobson NS, Christensen A. Integrative couple therapy: Promoting acceptance and change. WW Norton \& Co; 1996.

27. Chapman AL, Compton JS. From traditional behavioral couple therapy to integrative behavioral couple therapy: New research directions. The behavior analyst today. 2003; 4(1): 17 .

28. Atkins C.D, Baucom M.D, Chiristensen A, Eldridge A K. Infidelity and Behavioral Couple Therapy: optimism in the Face of Betrayal, journal of counsulting and clinical psychology.2005; 73(1): 144-150.

29. Christensen A, Atkins DC, Berns S, Wheeler J, Baucom DH, Simpson LE. Traditional versus integrative behavioral couple therapy for significantly and chronically distressed married couples. Journal of consulting and clinical psychology. 2004;72(2):176.

30. Zola MF. Beyond infidelity-related impasse: An integrated, systemic approach to couples therapy. Journal of systemic therapies. 2007; 26(2): 25-41.

31. Ebrahimi AE, Najafi MR, Mehrabi A, SadeghI Z. The Relation of Marital Conflict and Some of Socio-demographic Features with Migraine Headache Odds Ratio.Journal of Isfahan Medical School. 2008.

32. Lew A, Mckay M. Acceptance and Commitment therapy for Couples. Translated by Kashmiri $\mathrm{m}$ and Jalali. Publication arjmand. 2017.

33. Dimijian, S., Martell, C.R., Christensen, A..Integrative Behavioral Couple Therapy.In, A. J. Guramn \& N. S. Jacobson (Eds.), Clinical handbook of couple. 2002.

34. Morshedi M, Davarniya R, Zahrakar K, Mahmudi MJ, Shakarami M. The effectiveness 
of Acceptance and Commitment Therapy (ACT) on reducing couple burnout of couples. Iranian Journal of Nursing Research. 2016; 10(4): 7687.

35. Lashani L, Farhoudian A, Azkhosh M, Dolatshahee B, Saadati H. Acceptance and commitment therapy in the satisfaction of veterans with spinal cord injuries spouses. Iranian Rehabilitation Journal. 2013; 11(2): 5660 .

36. Mojtabaie M, Gholamhosseini S. Effectiveness of Acceptance and Commitment Therapy (ACT) to reduce the symptoms of anxiety in women with breast cancer. Journal of Social Issues \& Humanities. 2014;4(2):522-7.

37. Feros DL, Lane L, Ciarrochi J, Blackledge JT. Acceptance and Commitment Therapy (ACT) for improving the lives of cancer patients: a preliminary study. Psychooncology. 2013;22(2):459-64.

38. Khanizadeh Balderlou $\mathrm{K}$, Alizadeh $\mathrm{M}$, Kooraneh AE. The effectiveness of group Psychotherapy based on acceptance and commitment on quality of life in women with breast cancer. The Journal of Urmia University of Medical Sciences. 2016;27(5):365-74.

39. Coates AS, Hurny C, Peterson HF, Bernhard $\mathrm{J}$, Castinglione-Gertsch M, Gelberg D, Goldhirsch A. Quality of life scores predict outcome inmetastatic but not early breast. Cancer Study Group. J Clin Oncol. 2000; 18:3768-74.

40. Fraser SCA, RamirezAJ, Ebbes SR, Fallowfield LJ,Dobbs HJ, Richards MA, Bates T, Baum M. A daily diary for quality of life measurement in advanced breast cancer trials. Br J Cancer. 1993; 67:341-6.

41. Seidman AD, Portenoy R, Yao TJ, Lepore J, Mont EK, Kortmansky J, Onetto N, Ren L, Grechko J, BeltangadyMet al .Quality of life in phase II trialsa study of methodology and predictive value in patients with advanced breast cancer treated with paclitaxel, plus granulocyte colony stimulating factor. J Natl Cancer Inst.1995; 187:1316-22.

42. Goodwin JS, Zhang DD, Ostir GV. Effect of depression on diagnosis, treatment, and survival of older women with breast cancer. J Am Geriatr Soc .2004; 52:106-11.

43. Jacobson NS, Christensen A, Prince SE, Cordova J, Eldridge K. Integrative behavioral couple therapy: an acceptance-based, promising new treatment for couple discord. Journal of consulting and clinical psychology. 2000 ;68(2):351.

44. Christensen A, Atkins DC, Berns S, Wheeler J, Baucom DH, Simpson LE. Traditional versus integrative behavioral couple therapy for significantly and chronically distressed married couples. Journal of consulting and clinical psychology. 2004;72(2):176.

45. Heinrichs N, Zimmermann $\mathrm{T}$, Huber B, Herschbach P, Russell DW, Baucom DH. Cancer distress reduction with a couple-based skills training: a randomized controlled trial. Annals of Behavioral Medicine. 2011;43(2):239-52.

46. Montesi JL, Conner BT, Gordon EA, Fauber RL, Kim KH, Heimberg RG. On the relationship among social anxiety, intimacy, sexual communication, and sexual satisfaction in young couples. Archives of sexual behavior. 2013;42(1):81-91.

47. Koerner AF, Fitzpatrick M, Understanding family communication patterns and family functioning: The roles of conversation orientation and conformity orientation. Communication Year Book. 2013; (28): 3.

48. Snyder DK, Castellani AM, Whisman MA. Current status and future directions in couple therapy. Annu. Rev. Psychol.. 2006;57:317-44.

49. Shadish WR, Baldwin SA. Effects of behavioral marital therapy: a meta-analysis of randomized controlled trials. Journal of consulting and clinical psychology. 2005 ;73(1):6. 